\title{
Phenotyping of Weedy Rice to Assess Root Characteristics Associated with Allelopathy
}

\author{
Brooklyn Schumaker, Shandrea Stallworth, Auriana Tucker, Ziming Yue, Te-Ming Tseng* \\ Department of Plant and Soil Sciences, Mississippi State University, Mississippi State, MS, USA \\ Email: *t.tseng@msstate.edu
}

How to cite this paper: Schumaker, B., Stallworth, S., Tucker, A., Yue, Z. and Tseng, T.-M. (2021) Phenotyping of Weedy Rice to Assess Root Characteristics Associated with Allelopathy. American Journal of Plant Sciences, 12, 1210-1221. https://doi.org/10.4236/ajps.2021.128084

Received: June 22, 2021

Accepted: August 6, 2021

Published: August 9, 2021

Copyright $\odot 2021$ by author(s) and Scientific Research Publishing Inc. This work is licensed under the Creative Commons Attribution International License (CC BY 4.0).

http://creativecommons.org/licenses/by/4.0/ (c) (i) Open Access

\begin{abstract}
Weedy rice is a species of Oryza, and is a wild relative of cultivated rice. The weed possesses unique hardiness that allows them to thrive in dynamic and stressful environments. These characteristics suggest that weedy rice is a stored source of novel genes for competitive traits. One such trait is allelopathy, where a species releases secondary metabolites that suppress the growth and development of neighboring species. Weed competition is a limiting factor in rice production systems; therefore, it is critical to identify specific allelopathic weedy rice accessions to determine the genetic pathways and mechanisms associated with allelopathy to be used in breeding programs. Due to the complex nature of allelochemical production and the lack of knowledge of allelopathy mechanisms in weedy rice, phenotypic traits, particularly root traits, can be used to overcome this limitation and serve as target characteristics for breeding weed suppressive rice varieties. Five weedy rice accessions were chosen from preliminary screenings of larger sample sizes with the ability to suppress barnyardgrass weed seedling growth. Another five weedy rice with low barnyardgrass suppression was selected for the current root phenotypic study. Five cultivated rice lines were used as a comparison. All plants were propagated in a transparent germination pouch for four weeks. Roots were scanned and analyzed for root length and area covered. No differences were found in the seedling root area among weedy rice and rice accessions; however, allelopathic weedy rice plants exhibited a $14 \%$ increase in root length than non-allelopathic weedy rice plants. The allelopathic weedy rice accession B2 possessed the most extended root system $(22.4 \mathrm{~cm}$ root length). The highly allelopathic weedy rice accessions (including B2) screened and phenotyped in this study are ideal candidates for identifying the genetic controls of early root length, a possible trait contributing to underground allelopathic production and competitive advantage.
\end{abstract}

\section{Keywords}

Weed Suppression, Sustainable Agriculture, Integrated Weed Management, 
Barnyardgrass, Root System Architecture

\section{Introduction}

Plant root structures are notoriously difficult to study. Root system architecture (RSA) is defined as the spatial organization of roots and is crucial for normal root functioning. The RSA of a plant is affected by external factors such as water availability or nutrient stress. Roots have an innate ability to respond and adapt to external environmental factors, determining the plant's RSA and giving insight into the soil environment [1]. Phenotyping allelopathic root structures may provide insight into the plant's ability to thrive and adapt to environmental stresses [2]. Allelopathic interactions involve plants detecting neighbors and adjusting the production and excretion of chemicals as a defensive reaction. Detection of competitor plants is presumed to be due to triggering compounds being released into the soil [3] [4]. For instance, barnyardgrass releases allelochemicals into the rhizosphere, inducing increased production of allelochemicals in rice [3]. Even when plants are segregated belowground and have no physical root contact, the detection of chemicals still occurs [4]. Differences in defense pathways and allelochemical regulation between compounds have been found. Still, the mechanisms and genetic origins of allelopathic signaling and reactions need more attention [3] [4]. The genetic factors contributing to allelopathic root activity are still in the early stages of exploration; therefore, phenotyping provides information required for breeders to select traits associated with the high allelopathic activity [5]. Combined manual measurements, imaging, and computer programs to measure small root parts contribute to retrieving this hidden information. Allelopathic rice lines exhibit shallow soil depth for the majority of their root mass [2]. Soil depth preference may be one characteristic of root structure architecture contributing to weed suppression [2]. Information on root characteristics associated with wild rice types and the plant's vigorousness is limited. It has recently been noted that there are characteristic differences between wild rice and cultivated rice. Weedy rice root systems express deeper, thinner, straighter, and less spread out roots than cultivated rice, which are more abundant [6]. Research efforts to study root structures and how individual aspects relate to plant prosperity are slow, especially in allelopathic phenotypes, because root systems are difficult to observe without damaging the growing plant [1].

Methods for studying root structure architecture are limited. Many methods are destructive to the roots system making data difficult to obtain accurately [7]. Even the most minor root parts play a significant role in the plant's productivity. In some cases, the root hairs make up nearly $77 \%$ of the root area, comprising most rhizosphere coverage, where the bulk of the plants' nutrients is condensed [8]. In addition to viewing difficulties, root architecture is manipulated by the 
environment and growing conditions. Root architecture data collected from growing plants in controlled environments is not always relatable to field conditions [9]. Roots growing in an artificial medium should be trialed in a field setting similar to testing for allelopathy to compare results in different conditions [10]. Understanding the complexities of root architecture requires a combination of laboratory, field, and greenhouse methodologies [11].

Laboratory phenotyping methods require propagating the sample plant in non-soil media like gels or on paper and supplied with nutrient washes. After growth, root formation features and characteristics are determined by manual measurements or with 2-dimensional imaging [12] [13]. Soil extractions, imaging systems, or combinations of the two are standard field-root phenotyping techniques. The trench profile method, core break method, and shovelomics require soil cores to be cut and the soil removed from the roots to be measured [12]. Soil core samples support root distribution approximation measures [2]. The X-Ray Computed Tomography (X-Ray CT) images roots established in soil and is a non-destructive means of obtaining $3 \mathrm{D}$ root system images [7]. Researchers at the University of California Davis performed X-Ray CT and noted that the method was not well-developed [7]. Other reviews have highlighted the lack of standard procedures to separate soil and roots in the modeling process [14]. Limitations with X-Ray CT include the complicated equipment required for the survey and the extensive job of distinguishing roots against soils.

Consequently, the images obtained were not exceptionally clear but did give a broad depiction of the area covered. For example, small roots were not distinguishable from the soil matrix [7]. Similarly, shovelomics will generate a general structure of the root area, but the results lack detailed information on individual root parts [12]. Mathematical models employing fractural geometry create a reasonable estimate of root architecture measurements and aid in viewing root systems [1]. Measurements from 2-dimensional, planar models or images obtained from soil cores may serve as a base for $3 \mathrm{D}$ model construction. Although mathematical models can provide insight into root formation patterns, a failure results in accounting for natural recourses that significantly affect a plant's root structure [1]. Field observations of root systems are time-consuming and tedious but do garner useful general information [12]. There is a vital need for an accurate visual root architecture method.

Three-dimensional imaging software combined with MRI scanning techniques advances the prospect of using rice as an experimental subject for studying root structure [11]. The complete unique development of RSA can be obtained through 3D imaging techniques; additionally, this digital phenotypic data can be analyzed repeatedly for various traits [15] [16]. The limitations with these methods include the equipment needed, finding compatible soil media for these methods, and image processing time and software ability to distinguish soil from the root [17] [18].

Efforts to create bioassays for herbicide dose responses or observe root growth patterns gave way to germination pouches. This method is rapid, cost-efficient, 
reproducible, accurate, non-invasive, and easily controlled [19]. Germination pouches allow visualization of seedling growth patterns and have been utilized for various crops and purposes [20]. These transparent bags make it possible to promptly and practically observe and image roots at any growth stage. Screening in a lab setting allows for a uniform and controlled environment as well as sterile conditions. Images obtained can be analyzed and screened through publicly available user-friendly software programs. Adeleke et al. made germination pouches at an even lower cost than those purchased for this study and were able to successfully germinate seedlings and obtain photographs at the end of the study in less than five minutes per plant, producing fast and effective results [21]. This phenotyping strategy can increase non-invasive screenings by saving time and space in the seedling stage of development, leading to exploring traits in the accessions screened [21]. This study aimed to characterize root morphological traits of allelopathic and non-allelopathic weedy rice and identify root traits related to allelopathy.

\section{Materials and Methods}

\subsection{Plant Sample Preparation}

From Shrestha et al. [22], seeds of the five most barnyardgrass-suppressive (B81, S94, B2, B8, B14) and four least barnyardgrass-suppressive (B34, B83, S97, 84) weedy rice accession were selected. Cultivated rice lines Rex, Rondo, PI312777, CL163, and PI388046 were also included in this study for comparison. All seeds were surface-sterilized by soaking in $70 \%$ ethanol for 30 seconds and $5 \%$ bleach for 20 minutes and rinsed six times with distilled water. Sterilized seeds were germinated in plastic 9-cm Petri dishes lined with Whatman No. 1 filter paper and soaked with $5 \mathrm{ml}$ distilled water. Eight seeds from each accession were germinated for sprout selection. After germination, four seedlings of equal height were selected for each accession and placed using forceps into germination pouches (Mega international, Newport, MN). Pouches holding the seedlings were placed in the growth chamber in the Weed Physiology Laboratory at Mississippi State University, set at $30^{\circ} \mathrm{C} / 21^{\circ} \mathrm{C}$ day/night for 28 days after germination (DAG). Plants were watered with $20 \mathrm{ml}$ half-strength Hoagland's No. 2 basal salts (Caisson Laboratories, INC. Smithfield, UT) every two days to keep the roots damp until 28 DAG.

\subsection{Plant Imaging}

At 28 DAG, the bags were cut open, and the roots were removed and placed directly onto an Epson Perfection V370 Photo scanner (Epson America Inc, Long Beach CA). Black paper was placed over the root to contrast the image. Four images were obtained for each accession serving as individual replications. Root images were measured using Image ${ }^{\circledR}{ }^{\circledR}$ software (Image J, University of Wisconsin-Madison, WI). Each image was cropped to encompass the area each root covered and converted into an 8-bit grayscale format. The length of each root 
was recorded in $\mathrm{cm}$, and to obtain the total area covered by each root, the images were first converted to a binary format to remove the background and create a contrast.

\subsection{Statistical Analysis}

Accessions were considered as the fixed effect, while replications were considered as the random effects. The experimental design was a completely randomized design with four replications. Data were analyzed using a general linear model with mean values separated using Fisher's protected least significant difference at $\mathrm{p} \leq 0.05$. Data were analyzed using JMP $13\left(\mathrm{JMP}^{\circledast}\right.$, Version 13. SAS Institute Inc., Cary, NC, 1989-2007). Analysis of variance (ANOVA) was applied to compare the means of allelopathic and non-allelopathic weedy rice accessions root length and area.

\section{Results}

\subsection{Root Length and Area}

The root length and area of weedy rice and cultivated rice plants were measured (Tables 1-3). Weedy rice accession B2 showed the highest mean root length $(22.4 \mathrm{~cm})$ among the weedy rice accessions in this study (Table 1). Non-allelopathic weedy rice, $\mathrm{B} 83$, had the shortest mean root length $(7.4 \mathrm{~cm})$. Rex showed the longest roots among all accessions with a mean of $24.7 \mathrm{~cm}$. It should be noted that Rex and CL163 had only one replication in this study due to germination delays and were, therefore, excluded from the biotype groupings analysis.

Table 1. Mean root length $(\mathrm{cm})$ of weedy rice and cultivated rice accessions in ascending order at 28 days after germination. Means separated using Fisher's protected LSD ( $\alpha=$ $0.05)$, means with different letters denote a significant difference.

\begin{tabular}{cc}
\hline Accession & Mean Root Length $(\mathrm{cm})$ \\
\hline B83 & $7.4 \mathrm{f}$ \\
Bondo & $8.5 \mathrm{e}-\mathrm{f}$ \\
CL163 & $9.2 \mathrm{c}-\mathrm{f}$ \\
B8 & $9.8 \mathrm{~d}-\mathrm{f}$ \\
B84 & $11.0 \mathrm{~b}-\mathrm{e}$ \\
B34 & $15.9 \mathrm{a}-\mathrm{e}$ \\
S97 & $16.9 \mathrm{a}-\mathrm{d}$ \\
S94 & $16.9 \mathrm{a}-\mathrm{d}$ \\
PI338046 & $17.7 \mathrm{a}-\mathrm{c}$ \\
PI312777 & $18.9 \mathrm{a}-\mathrm{c}$ \\
B14 & $19.4 \mathrm{ab}$ \\
B2 & $21.7 \mathrm{a}$ \\
Rex & $22.4 \mathrm{a}$ \\
\hline
\end{tabular}


Table 2. Allelopathic weedy rice, non-allelopathic weedy rice, and cultivated rice mean root lengths $(\mathrm{cm})$ and areas $\left(\mathrm{cm}^{2}\right)$ at 28 days after germination. Means separated using Fisher's protected LSD ( $\alpha=0.05)$, means with different letters denote a significant difference.

\begin{tabular}{ccc}
\hline Biotype Group & Mean Root Length $(\mathrm{cm})$ & Mean Root Area $\left(\mathrm{cm}^{2}\right)$ \\
\hline Allelopathic weedy rice & $17.5 \mathrm{a}$ & $2.2 \mathrm{a}$ \\
Non-Allelopathic weedy rice & $15.3 \mathrm{a}$ & $2.3 \mathrm{a}$ \\
Cultivated rice & $17.0 \mathrm{a}$ & $1.9 \mathrm{a}$ \\
\hline
\end{tabular}

Table 3. Mean root area $\left(\mathrm{cm}^{2}\right)$ of weedy rice and rice accessions in ascending order at 28 days after germination. Means separated using Fisher's protected LSD $(\alpha=0.05)$, means with different letters denote a significant difference.

\begin{tabular}{cc}
\hline Accession & Mean Root Area $\left(\mathrm{cm}^{2}\right)$ \\
Rondo & $0.8 \mathrm{f}$ \\
CL163 & $1.1 \mathrm{ef}$ \\
B84 & $1.4 \mathrm{ef}$ \\
B8 & $1.5 \mathrm{ef}$ \\
B81 & $1.7 \mathrm{de}$ \\
PI312777 & $1.9 \mathrm{c}-\mathrm{e}$ \\
PI338046 & $2.1 \mathrm{~b}-\mathrm{e}$ \\
B2 & $2.2 \mathrm{a}-\mathrm{d}$ \\
S94 & $2.3 \mathrm{a}-\mathrm{d}$ \\
B14 & $2.4 \mathrm{a}-\mathrm{c}$ \\
Rex & $2.6 \mathrm{ab}$ \\
S97 & $2.6 \mathrm{a}-\mathrm{d}$ \\
B34 & $2.6 \mathrm{ab}$ \\
\hline
\end{tabular}

Weedy rice was characterized as allelopathic or non-allelopathic based on data from a screening performed in a prior study [22]. Allelopathic weedy rice consisted of accessions B84, S94, B81, and B2 with moderate to high barnyardgrass suppression, while non-allelopathic accessions were S97, B83, B8, B14, and B34 with low barnyardgrass suppression. No differences were found between allelopathic weedy rice and non-allelopathic weedy rice biotypes in terms of root length (Table 2). Allelopathic weedy rice had a mean root length of $17.5 \mathrm{~cm}$, similar to cultivated rice $(17 \mathrm{~cm})$. Non-allelopathic weedy rice, on the other hand, had a mean root length of $15.3 \mathrm{~cm}$. No changes were observed in the statistical significance between biotypes by excluding or including these accessions in the cultivated rice group.

No differences were observed among allelopathic weedy rice, non-allelopathic weedy rice, and cultivated rice based on the root area (Table 2). However, the non-allelopathic rice cultivar Rex showed the greatest root coverage $\left(2.6 \mathrm{~cm}^{2}\right)$, 
while the allelopathic cultivated rice Rondo showed the least $\left(0.8 \mathrm{~cm}^{2}\right)$ root area among the cultivated rice (Table 3). Weedy rice accession B34 $\left(2.8 \mathrm{~cm}^{2}\right)$ had the greatest root area of all accessions. Allelopathic rice had a slightly larger root area $\left(2.2 \mathrm{~cm}^{2}\right)$ than the other two biotypes, cultivated rice $\left(1.9 \mathrm{~cm}^{2}\right)$ and non-allelopathic weedy rice $\left(2.3 \mathrm{~cm}^{2}\right)$.

\subsection{Correlations}

Correlation analysis was run on root measurements to determine the relationship between allelopathy and root length and area (Figure 1 and Figure 2). A positive correlation was found between root length and allelopathic suppression (Figure 1). The Pearson correlation statistic was 0.26 , indicating a positive correlation. The Spearman's correlation was 2.4, consistent with the Pearson correlation results.

A negative correlation was found between the root area and allelopathy (Figure 2). The Spearman's correlation was used due to an abnormal distribution of the root area and was -0.02 .

\section{Discussion}

The allelopathic weedy rice accessions had longer roots when plants were 4-weeks old. The non-allelopathic weedy rice, on the other hand, had shorter roots, but none of the groups were statistically different from each other. The roots of the non-allelopathic group observed had higher numbers of secondary roots and branched more than the allelopathic biotype resulting in a similar total root area. Allelopathic weedy rice, both black hull and straw hull accessions,

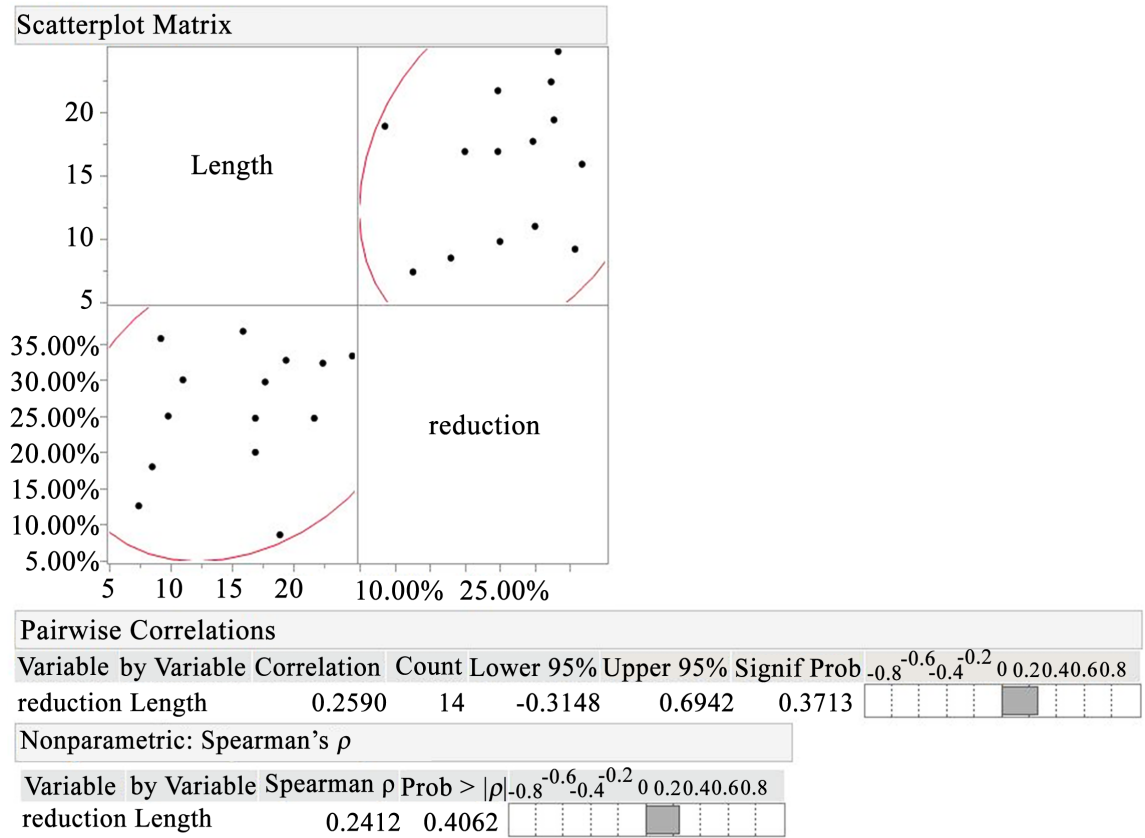

Figure 1. Correlation between root length $(\mathrm{cm})$ of rice plants and their allelopathic potential against barnyardgrass. 


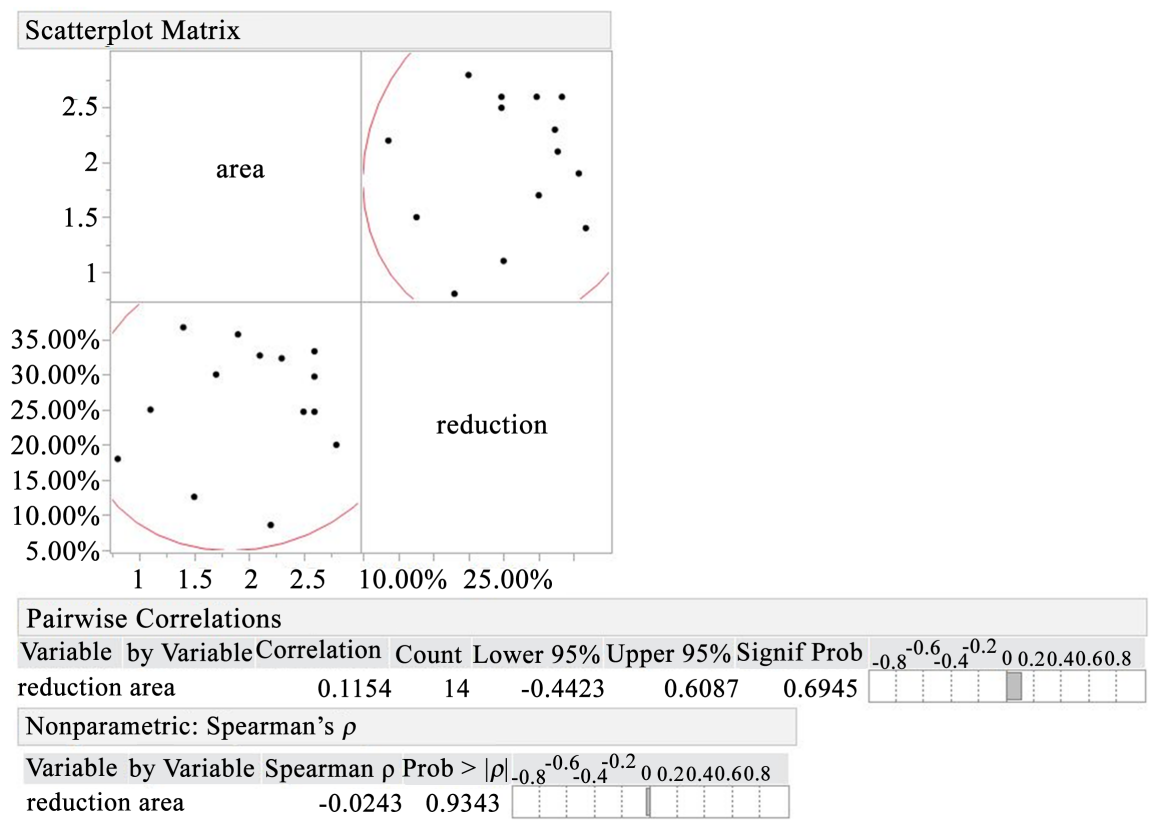

Figure 2. Correlation between root area $\left(\mathrm{cm}^{2}\right)$ of rice plants and their allelopathic potential against barnyardgrass.

have deeper rooting than cultivated rice 13 days after germination [6]. The present study assessed seeds 21 days after germination and included both hull types of weedy rice and found similar results. Three of the cultivated rice accessions used in this study were weed suppressive. They may have been the reason for the similarity between the allelopathic weedy rice groups and the cultivated rice groups. Highly allelopathic weedy rice accession B2 with more extended root systems is a candidate for further study for competitive root traits.

As observed in the present study, the root area was not different between the allelopathic $\left(2.2 \mathrm{~cm}^{2}\right)$ and non-allelopathic accession $\left(2.3 \mathrm{~cm}^{2}\right)$ groups. However, in our previous study, these two groups differed in their allelopathic potential against barnyardgrass, ranging from about $20 \%-60 \%$ [22]. Non-suppressive rice showed larger root areas and shorter roots than did suppressive rice. Differences have been noted in the rice crop root morphology and the weedy rice root morphology that may have contributed to these findings. A study that measured 98 different root architecture parameters in crops found their roots higher in the soil profile, more widespread, and abundant [23]. In this study and Wedger et al. [23], root length is measured as that distance between the soil line and the longest root 90 degrees from the soil line. Multiple weed accessions, on average, had deeper or longer roots than the crop lines. The rice crop has been characterized to have a more exploratory root pattern similar to our total area measurement [23]. The morphological differences between weedy rice and rice were observed in this study. Still, the results show little difference between allelopathic and non-allelopathic weedy rice root length and total area during the seedling stage. This lack of difference may be due to either the growth stage, the two groups exhibiting similar weedy characteristics distinguishable from the crop, or the 
presence of additional parameters not noted here that may distinguish between the two.

Allelopathic cultivars are classified based on isozymes belonging to different environments suggesting divergent evolutionary origins [24] [25]. Generally, weed suppressive cultivars fall in the tropical Japonica groups [24]. In contrast, other studies have found that indica rice lines have higher weed suppressive abilities in the field than Japonica [2] [26]. The cultivars used in this study were a mix of groups based on their origin compared to the weed suppressive accessions, all belonging to the indica group with similarly long slender seedling roots as weedy rice. This group is noted for its thin superficial root systems [25]. Weedy rice PI312777 had the longest roots in this study. The results presented are coherent with previous studies regarding root phenotypes and genetic backgrounds [2] [25]. The cultivated rice in this study in terms of root length was similar to the allelopathic weedy rice. Weedy rice characteristics include deep, thin, and straight roots like the indica rice [6], while Rex is a japonica variety noted for its deep, thick, and extensive root system [25]. The present study assessed two characteristics focusing on seedling length in which Rex performed well but was missing data and could not be confidently compared as an individual accession. The allelopathic weedy rice group had the longest roots in this study. Deep and long roots have been associated with stress adaptability during the early plant stages, such as in drought-tolerant rice [27]. Another study on identifying QTLs associated with drought tolerance using differing water regimes found tolerant rice accession Azucena to exhibit thicker roots with higher mass deep in the soil profile [28]. Root plasticity under stressful conditions increases when parameters such as root length, width, and number were measured in other studies [29]. Allelopathic plants may have the ability, in addition to releasing allelochemicals into the soil, to adapt to stresses such as competition from weeds by altering their root architecture. Experiments to understand how weedy rice growth patterns change in the presence of a competitor such as barnyardgrass could provide exciting insights into the behavior of highly allelopathic accessions under the soil surface.

\section{Conclusion}

Laboratory screenings lack natural soil profiles as found under field conditions but allow precise measurements. By controlling the environment, morphological characteristics apart from the environment can be expressed and studied. Weedy rice displayed a variety of different root lengths and areas. With respect to root length, allelopathic weedy rice showed longer seedling roots than non-allelopathic biotypes. Early seedling vigor and the stage at which the accessions were screened could play a role in how the roots were expressed in this study. The highly allelopathic weedy rice accessions screened and phenotyped are ideal candidates for identifying the genetic controls of early root length, a possible trait contributing to underground allelopathic production and competitive ad- 
vantage. More root architecture traits may contribute to underground allelopathic interaction, but these findings serve as a single piece of a complex puzzle. As seen in allelopathic and suppressive indicia varieties, long seedling roots may provide a target for enhancing the allelopathic potential in rice and offer a competitive advantage to the crop.

\section{Acknowledgements}

Funding for this project was provided by the Special Research Initiative Grant sponsored by the Mississippi Agricultural and Forestry Experiment Station and is based upon work that is supported by the National Institute of Food and Agriculture, U.S. Department of Agriculture, Hatch project under accession number 230100. The authors would like to thank Grace Fuller and Swati Shrestha for their intellectual and technical assistance throughout the project.

\section{Conflicts of Interest}

The authors declare no conflicts of interest regarding the publication of this paper.

\section{References}

[1] Lynch, J. (1995) Root Architecture and Plant Productivity. Root Architecture and Plant Productivity, Plant Physiology, 109, 7-13. https://doi.org/10.1104/pp.109.1.7

[2] Gealy, D., Moldenhauer, K. and Duke, S. (2013) Root Distribution and Potential Interactions between Allelopathic Rice, Sprangletop (Leptochloa spp.), and Barnyardgrass (Echinochloa crus-galli) Based on 13C Isotope Discrimination Analysis. Journal of Chemical Ecology, 39, 186-203. https://doi.org/10.1007/s10886-013-0246-7

[3] Li, J.Y., Guo, X.K., Zhang, Q., Liu, C.H., Lin, Z.H., Yu, Z.M., He, H.B., et al. (2015) A Novel Screening Method for Rice Allelopathic Potential: The Inhibitory-Circle Method. Weed Research, 55, 441-448. https://doi.org/10.1111/wre.12166

[4] Kong, C.H., Li, H.B., Hu, F., Xu, X.H. and Wang, P. (2006) Allelochemicals Released by Rice Roots and Residues in Soil. Plant and Soil, 288, 47-56. https://doi.org/10.1007/s11104-006-9033-3

[5] Sandhu, N., Raman, K.A., Torres, R.O., Audebert, A., Dardou, A., Kumar, A. and Henry, A. (2016) Rice Root Architectural Plasticity Traits and Genetic Regions for Adaptability to Variable Cultivation and Stress Conditions. Plant Physiology, 171, 2562-2576. https://doi.org/10.1104/pp.16.00705

[6] Wedger, M.J., Topp, N.C. and Olsen, M.K. (2019) Convergent Evolution of Root Systems Architecture in Two Independently Evolved Lineages of Weedy Rice. New Phytologist, 223, 1031-1042. https://doi.org/10.1111/nph.15791

[7] Heeraman, D.A., Hopmans, J.W. and Clausnitzer, V. (1997) Three-Dimensional Imaging of Plant Roots In Situ with X-Ray Computed Tomography. Plant and Soil, 189, 167-179. https://doi.org/10.1023/B:PLSO.0000009694.64377.6f

[8] Bertin, C., Yang, X. and Weston, L.A. (2003) The Role of Root Exudates and Allelochemicals in the Rhizosphere. Plant and Soil, 256, 67-83. https://doi.org/10.1023/A:1026290508166

[9] Dorlodot, S.D., Forster, B., Pages, L., Price, A., Tuberosa, A. and Draye, X. (2007) 
Root System Architecture: Opportunities and Constraints for Genetic Improvement of Crops. Trends in Plant Science, 12, 474-481. https://doi.org/10.1016/j.tplants.2007.08.012

[10] Nestler, J., Keyes, S.D. and Wissuwa, M. (2016) Root Hair Formation in Rice (Oryza sativa L.) Differs between Root Types and Is Altered in Artificial Growth Conditions. Journal of Experimental Botany, 67, 3699-3708.

https://doi.org/10.1093/jxb/erw115

[11] Kochian, L.V. and Holley, R.W. (2011) High-Throughput 3-Dimensional Root Phenotyping Plant Physiology Preview.

[12] Walter, A., Liebisch, F. and Hund, A. (2015) Plant Phenotyping: From Bean Weighing to Image Analysis. Plant Methods, 11, 14. https://doi.org/10.1186/s13007-015-0056-8

[13] Zhu, J., Ingram, P.A., Benfey, P.N. and Elich, T. (2011) From Lab to Field, New Approaches to Phenotyping Root System Architecture. Current Opinion in Plant Biology, 14, 310-317. https://doi.org/10.1016/j.pbi.2011.03.020

[14] Metzner, R., Eggert, A., van Dusschoten, D., et al. (2015) Direct Comparison of MRI and X-Ray CT Technologies for 3D Imaging of Root Systems in Soil: Potential and Challenges for Root Trait Quantification. Plant Methods, 11, Article No. 17. https://doi.org/10.1186/s13007-015-0060-Z

[15] Topp, C.N., Iyer-Pascuzzi, A.S., Anderson, J.T., Lee, C.-R., Zurek, P.R., Symonova, O., Zheng, Y., Bucksch, A., Mileyko, Y., Galkovskyi, T., Moore, B.T., Harer, J., Edelsbrunner, H., Mitchell-Olds, T., Weitz, J.S. and Benfey, P.N. (2013) 3D Phenotyping and Quantitative Trait Locus Mapping Identify Core Regions of the Rice Genome Controlling Root Architecture. Proceedings of the National Academy of Sciences, 110, E1695-E1704. https://doi.org/10.1073/pnas.1304354110

[16] Clark, R.T., MacCurdy, R.B., Jung, J.K., Shaff, J.E., McCouch, S.R., Aneshansley, D.J. and Kochian, L.V. (2011) Three-Dimensional Root Phenotyping with a Novel Imaging and Software Platform. Plant Physiology, 156, 455-465.

https://doi.org/10.1104/pp.110.169102

[17] Pflugfelder, D., Metzner, R., van Dusschoten, D., et al. (2017) Non-Invasive Imaging of Plant Roots in Different Soils Using Magnetic Resonance Imaging (MRI). Plant Methods, 13, 102. https://doi.org/10.1186/s13007-017-0252-9

[18] Flavel, R.J., Guppy, C.N., Tighe, M., Watt, M., McNeill, A. and Young, I.M. (2012) Non-Destructive Quantification of Cereal Roots in Soil Using High-Resolution X-Ray Tomography. Journal of Experimental Botany, 63, 2503-2511. https://doi.org/10.1093/jxb/err421

[19] Zhang, C.J., Lim, S.H., Kim, J.W., Song, M., Yook, M.J., Nah, G., Valverde, B.E. and Kim, D.S. (2015) Quantifying Herbicide Dose Response and Resistance in Echinichoa ssp. by Measuring Root Length in Growth Pouches. Canadian Journal of Plant Science, 95, 1181-1192. https://doi.org/10.4141/cjps-2015-122

[20] You, J., Hu, Y. and Wang, C. (2018) Application of Seed Germination Pouch for Culture and Initial Resistance Screening of the Soybean Cyst Nematode Heterodera glycines. Nematology, 2, 1568-5411. https://doi.org/10.1163/15685411-00003184

[21] Adeleke, E., Millas, R., McNeal, W., Faris, J. and Taheri, A. (2019) Assessing Root System Architecture of Wheat Seedlings Using A High-Throughput Root Phenotyping System. https://doi.org/10.1101/677955

[22] Shrestha, S., Burgos, N.R. and Tseng, T.M. (2020) Competitive Ability of Weedy Rice: Toward Breeding Weed-Suppressive Rice Cultivars. Journal of Crop Improvement, 34, 455-469. https://doi.org/10.1080/15427528.2020.1733158 
[23] Wedger, M.J., Topp, C.N. and Olsen, K.M. (2019) Convergent Evolution of Root System Architecture in Two Independently Evolved Lineages of Weedy Rice. New Phytologyst, 223, 1031-1042. https://doi.org/10.1111/nph.15791

[24] Jensen, L.B., Courtois, B., Shen, L., Li, Z., Olofsdotter, M. and Mauleon, R.P. (2001) Locating Genes Controlling Allelopathic Effects against Barnyardgrass in Upland Rice. Agronomy Journal, 93, 21. https://doi.org/10.2134/agronj2001.93121x

[25] Lafitte, R.H., Champoux, M.C., McLaren, G. and O’Toole J.C. (2001) Rice Root Morphological Traits Are Related to Isozyme Groups and Adaption. Field Crops Research, 71, 57-70. https://doi.org/10.1016/S0378-4290(01)00150-2

[26] Worthington, M. and Reberg-Horton, C. (2013) Breeding Cereal Crops for Enhanced Weed Suppression: Optimizing Allelopathy and Competitive Ability. Journal of Chemical Ecology, 39, 213-231. https://doi.org/10.1007/s10886-013-0247-6

[27] Courtois, B., Ahmadi, N., Khowaja, F., Price, A.H., Rami, J., Frouin, J., Hamelin, C. and Ruiz, M. (2009) Rice Root Architecture: Meta Analysis from a Drought QTL Database. Rice, 2, 115-128. https://doi.org/10.1007/s12284-009-9028-9

[28] Price, A.H., Steele, K.A., Gorham, J., Bridges, J.M., Moore, B.J., Evans, J.L., Richardson, P. and Jones, R.G.W. (2002) Upland Rice Grown in Soil-Filled Chambers and Exposed to Contrasting Water-Deficit Regimes: I. Root Distribution, Water Use and Plant Water Status. Field Crops Research, 76, 11-24. https://doi.org/10.1016/S0378-4290(02)00012-6

[29] Sandhu, N., Raman, A.K.Z., Torres, R.O., Audebert, A., Dardou, A., Kumar, A. and Henry, A. (2016) Rice Root Architectural Plasticity Traits and Genetic Regions for Adaptability to Variable Cultivation and Stress Conditions. Plant Physiology, 171, 2562-2576. https://doi.org/10.1104/pp.16.00705 